OPEN ACCESS

Edited by:

Mario Alberto Rodriguez,

Centro de Investigación y de Estudios

Avanzados del Instituto Politécnico

Nacional, Mexico

Reviewed by:

Anjan Debnath,

University of California, San Diego,

United States

Thomas Jacobs,

Bernhard-Nocht-Institut für

Tropenmedizin, Germany

${ }^{*}$ Correspondence: Consuelo Gómez García cgomezg@ipn.mx

Received: 07 August 2017 Accepted: 15 November 2017

Published: 29 November 2017

Citation:

Nieto A, Pérez Ishiwara DG, Orozco E,

Sánchez Monroy $V$ and

Gómez García C (2017) A Novel Heat

Shock Element (HSE) in Entamoeba

histolytica that Regulates the

Transcriptional Activation of the

EhPgp5 Gene in the Presence of

Emetine Drug

Front. Cell. Infect. Microbiol. 7:492.

doi: 10.3389/fcimb.2017.00492

\section{A Novel Heat Shock Element (HSE) in Entamoeba histolytica that Regulates the Transcriptional Activation of the EhPgp5 Gene in the Presence of Emetine Drug}

\author{
Alma Nieto ${ }^{1}$, David G. Pérez Ishiwara ${ }^{1}$, Esther Orozco ${ }^{2}$, Virginia Sánchez Monroy ${ }^{1}$ and \\ Consuelo Gómez García ${ }^{1 *}$
}

'Laboratorio de Biomedicina Molecular I, Escuela Nacional de Medicina y Homeopatía, Instituto Politécnico Nacional, Mexico City, Mexico, ${ }^{2}$ Departamento de Infectómica y Patogénesis Molecular, Centro de Investigación y de Estudios Avanzados del Instituto Politécnico Nacional, Mexico City, Mexico

Transcriptional regulation of the multidrug resistance EhPgp5 gene in Entamoeba histolytica is induced by emetine stress. EhPgp5 overexpression alters the chloride-dependent currents that cause trophozoite swelling, diminishing induced programmed cell death (PCD) susceptibility. In contrast, antisense inhibition of P-glycoprotein (PGP) expression produces synchronous death of trophozoites and the enhancement of the biochemical and morphological characteristics of PCD induced by G418. Transcriptional gene regulation analysis identified a 59 bp region at position -170 to -111 bp promoter as putative emetine response elements (EREs). However, insights into transcription factors controlling EhPgp5 gene transcription are missing; to fill this knowledge gap, we used deletion studies and transient CAT activity assays. Our findings suggested an activating motif ( -151 to $-136 \mathrm{bp}$ ) that corresponds to a heat shock element (HSE). Gel-shift assays, UV-crosslinking, binding protein purification, and western blotting assays revealed proteins of 94, 66, 62, and $51 \mathrm{kDa}$ binding to the EhPgp5 HSE that could be heat shock-like transcription factors that regulate the transcriptional activation of the EhPgp5 gene in the presence of emetine drug.

\section{Keywords: multidrug resistance, HSE, Entamoeba histolytica, EhPgp5, emetine, stress}

\section{INTRODUCTION}

The multidrug resistance phenotype (MDR) is a phenomenon in which the cell is able to survive in the presence of a drug and shows cross-resistance to a variety of structurally unrelated drugs across membranes in a wide range of organisms (Moons, 2003). The MDR phenotype has been identified in several organisms from mammals to prokaryotes provoking serious problems for the treatment and control of different illness, such as cancer, sepsis, and several parasitoses, such as malaria, leishmaniasis, and others (Juranka et al., 1989).

The P-glycoprotein (PGP) an ATP-dependent membrane-bound transporter is the major protein involved in the MDR phenotype (Mickley et al., 1989). In humans, the PGP is encoded 
by two $M D R$ genes (MDR1 and MDR3) (Chin et al., 1989); in mice, by mdr1a and mdr1b (Cui et al., 2009); in Leishmania major, by $l m m d r 1$ and $l m m d r 2$; and in Plasmodium falciparum, by $p f m d r 1$ and the $p f m d r 2$ (Grogl et al., 1991). Interestingly, the largest $m d r$ gene family described until now is present in Entamoeba histolytica (Orozco et al., 2001), the protozoan parasite responsible for human amoebiasis, which causes an estimated 50 million cases of invasive disease and 70,000 deaths per year (World Health Organization, 1998). The multigenic amoeba $m d r$ family is composed of EhPgp1, EhPgp2, EhPgp5, and EhPgp6 genes. A differential gene expression pattern has been documented in drug-sensitive (clone A) and drug-resistant (clone C2) trophozoites (Descoteaux et al., 1995). EhPgp1 is constitutively expressed in trophozoites from clones A and C2 (Gómez et al., 1996). In contrast, the EhPgp5 gene showed inducible expression due to the presence of emetine in culture medium (Descoteaux et al., 1995). The transcript of this gene was not detected in clones A and C2 growth without drug. However, when $\mathrm{C} 2$ trophozoites were cultured in the presence of emetine, expression of the EhPgp5 gene increased in a drug concentrationdependent manner (Descoteaux et al., 1995). Although an increase in the EhPgp5 mRNA half-life was reported (LópezCamarillo et al., 2003), its expression was mainly dependent on transcriptional activation (Pérez et al., 1998). The EhPgp5 promoter region, from -170 to $+30 \mathrm{bp}$, was able to efficiently drive the expression of CAT reporter gene when trophozoites from clones A and C2 were cultured under drug pressure (Pérez et al., 1998), suggesting that specific emetine response elements (EREs) were present in this region. Additionally, functional assays suggested that the putative ERE could be localized between -170 and -111 bp of the EhPgp5 gene promoter (Nieto et al., 2005).

To investigate the relevance of ERE to EhPgp5 gene transcription, deletions, and transient CAT activity studies were performed here. Our findings suggested an activating motif ( -151 to $-136 \mathrm{bp})$ that corresponds to a heat shock element (HSE). Gel-shift assays, UV-crosslinking, binding protein purification, and western blotting assays revealed proteins binding to the EhPgp5 HSE that could be heat shock-like transcription factors, which regulate transcriptional activation of the EhPgp5 gene in the presence of emetine drug.

\section{MATERIALS AND METHODS}

\section{E. histolytica Cultures}

Trophozoites of clones A and C2 (strain HM1: IMSS) (Orozco et al., 1985) were axenically cultured in TY1-S-33 medium (Diamond et al., 1978). Emetine stress was exerted by the incubation of trophozoites from clones A or C2 in 8 or $20 \mu \mathrm{M}$ emetine, respectively, for $24 \mathrm{~h}$.

\section{In Silico Search for Potential Transcription Binding Sites}

The TRANSFACT database (MatInspector software) was used to identify potential transcription factor binding sites in the EhPgp5 promoter (Matys et al., 2006).

\section{Plasmid Constructions}

To perform transfection experiments, several plasmids were constructed by inserting PCR-amplified EhPgp5 gene core promoter fragments into multiple cloning sites of the pBSCATACT plasmid (Gómez et al., 1998). The constructs performed are shown in Figures 1A,B. Constructs with specific mutations in the CdxA, YY1, and HSE regions were performed by PCR amplification using the primers shown in Figure 1C. Promoterless (pBSCAT-ACT) and minimal p259Pgp5 promoter constructs (Pérez et al., 1998) were used as negative and positive controls, respectively. The $\mathrm{pA} 5^{\prime} \mathrm{A} 3^{\prime} \mathrm{CAT}$ plasmid (Nickel and Tannich, 1994), which contains a $480 \mathrm{bp}$ fragment from the actin gene promoter, was used as an internal control of transfection efficiency. Correct sequence orientation of the cloned fragments was determined by sequencing analysis.

\section{Transfection and Cat Assays}

Transfection assays were performed by electroporation (Nickel and Tannich, 1994). Briefly, $10^{6}$ trophozoites of clones A and C2 were transfected with $100 \mu \mathrm{g}$ of the different plasmid constructs $(\Delta \mathrm{CdxA}$-Pgp5, $\Delta$ CdxA-YY1-Pgp5, $\Delta$ 5HSE-Pgp5, pmuCdxAPgp5, pmuYY1cPgp5, pmuYY1gPgp5, pmuHSEPgp5, pmHSE-TTCPgp5, p-sinHSEPgp5, p259Pgp5, pBSCAT-ACT, and $\left.\mathrm{pA} 5^{\prime} \mathrm{A} 3^{\prime} \mathrm{CAT}\right)$. Electroporated trophozoites were transferred into plastic flasks (Nalgene, NY, USA) containing $50 \mathrm{ml}$ of TYI-S-33 medium and were incubated for $48 \mathrm{~h}$ at $37^{\circ} \mathrm{C}$. Two hours after electroporation, we added $8 \mu \mathrm{M}$ emetine to clone A or $20 \mu \mathrm{M}$ emetine to clone C2. CAT activities were measured by two-phase diffusion assay using $5 \mu \mathrm{g}$ of trophozoite extracts and $200 \mu \mathrm{l}$ of chloramphenicol $(1.25 \mathrm{mM})$, which were incubated with $\left[{ }^{14} \mathrm{C}\right]$-butyril-CoA (NEN Life Science Products, MA, USA) for $2 \mathrm{~h}$. Protein concentrations were determined using Bradford's methods (Bradford, 1976). CAT activities were expressed as the cpm of the butyrylated derivatives. The background obtained from the trophozoites transfected with the pBSCAT-ACT plasmid was subtracted from the measurements given by the plasmids containing the different promoter constructions. CAT activities were determined in the linear range of assays, representing three independent experiments performed in triplicate. The efficiency of the transfection experiments was monitored by the activity of $\mathrm{pA} 5^{\prime} \mathrm{A} 3^{\prime} \mathrm{CAT}$ plasmid (Nickel and Tannich, 1994).

\section{Nuclear Extracts (NEs)}

NEs were prepared from trophozoites of clones $\mathrm{A}$ and $\mathrm{C} 2$ grown in the presence [clones $\mathrm{A}_{(8)}$ and $\mathrm{C}_{(20)}$ ] or absence (clones A and C2) of emetine, following Schreiber et al.'s protocol (Schreiber et al., 1989), modified by Gómez et al. (1998). Protein concentrations were determined by Bradford's methods (Bradford, 1976).

\section{Electrophoretic Mobility Gel-Shift Assays}

Double-stranded oligonucleotides of the EhPgp5 HSE sequence from -150 to $-137 \mathrm{bp}$ (HSE-S-16, 5' -ATAGAAATTTTTCATA$3^{\prime}$ ) were synthesized and labeled using $\mathrm{T} 4$ polynucleotide kinase (Invitrogen, CA, USA) in the presence of $\left[\gamma^{-32} \mathrm{P}\right]-$ ATP. Specific activity was determined by scintillation counting. 


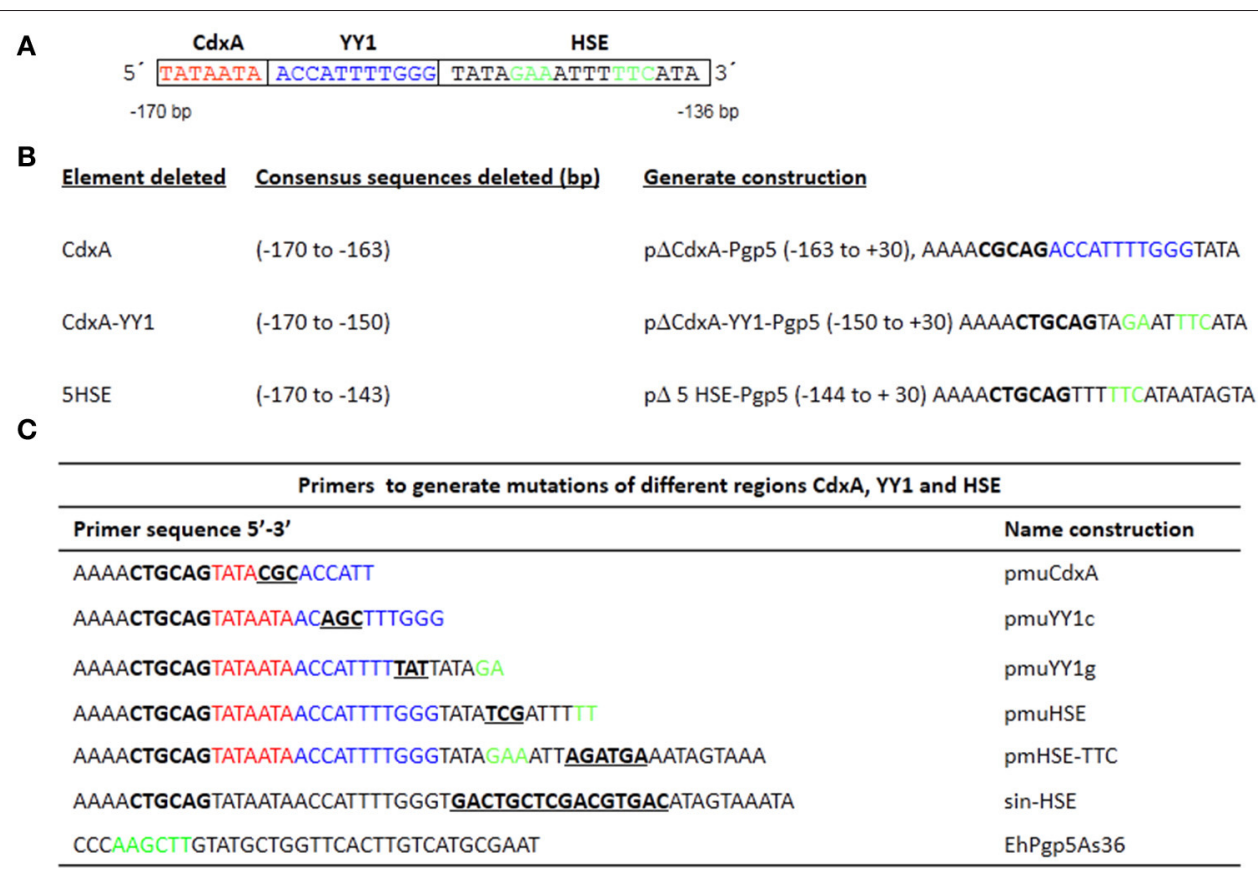

FIGURE 1 | Plasmid constructions in the EhPgp5 gene core promoter. (A) Schematic representation of three consensus sequences in the EhPgp5 gene promoter (-170 to -136 bp). CdXA, YY1, and HSE motifs are marked in red, blue, and green in the rectangles, respectively. (B) Constructs generated by deletion of each consensus sequence of the EhPgp5 gene core promoter (-170 to -136 bp). (C) Primers used to generate different mutations in CdXA, YY1, and HSE motifs. Mutations are underlined and bolded in black. Restriction sites for Pstl and Hind III are bolded in black. The last sequence is the antisense primer used for all constructs.

Gel-shift assays were performed in triplicate as described previously (Gómez et al., 1998). Briefly, we used 0.5-1 ng of labeled probes $(10,000 \mathrm{cpm}), 1 \mu \mathrm{g}$ of poly [d (I-C)] (Amersham Pharmacia Biotech, NJ, USA), $20 \mu \mathrm{g}$ of NE from trophozoites and 10\% glycerol in DNA-protein binding buffer. For competition assays, 150-fold molar excess of unlabeled oligonucleotides was incubated with $\mathrm{NE}$ at $4^{\circ} \mathrm{C}$ for $10 \mathrm{~min}$ prior to adding the radiolabeled probes. As competitors, we used poly [d (I-C)] and the double-stranded oligonucleotides S34 (5'-TATAATAACCATTTTGGGTATAGAAATTTTTCAT-3') and HSEm ( $5^{\prime}$-ATATCGATTTTTCATA-3').

\section{UV-Crosslinking and Western Blot Experiments}

UV-crosslinking assays were performed according to Ausubel et al. (1994) with some modifications. Standard gel-shift mixtures using NE from trophozoites of both clones grown in the absence or presence of emetine and the radiolabeled HSE probe were scaled up five-fold and were exposed to irradiation in a $312 \mathrm{~nm}$ UV-transilluminator (Bio-Rad, CA, USA) for $10 \mathrm{~min}$ at $4^{\circ} \mathrm{C}$; then, the proteins were separated by $15 \%$ SDSPAGE (Laemmli, 1970). The gels were dried and analyzed by autoradiography. DNA cross-linked proteins were analyzed by western blot using the standard procedure (Ausubel et al., 1994). The membranes were incubated with $2 \mu \mathrm{g}$ of human anti-HSF1 (H-311, Santa Cruz Biotechnology, TX, USA) in
$5 \%$ non-fat dry milk and $0.05 \%$ Tween-20 in phosphatebuffered saline (PBS), with a $\mathrm{pH}$ of 7.4 , overnight at $4^{\circ} \mathrm{C}$. The proteins were revealed by peroxidase-conjugated antirabbit secondary antibodies (ZYMED Laboratories, CA, USA) (1:3000) and were immunodetected by a chemiluminescence system (ECL Plus TM, Amersham Pharmacia Biotech, NJ, USA). The assays were repeated at least three times for each studied condition.

\section{Purification of E. Histolytica Proteins}

E. histolytica proteins that bind to the HSE sites of the EhPgp5 gene core promoter were partially purified three separate times under non-denaturing conditions using a DNA-binding protein purification kit (Roche, CA, USA) and NE from trophozoites of both clones $\mathrm{A}_{[8]}$ and $\mathrm{C}_{[20]}$. Concatemeric polynucleotides were prepared by PCR amplification of the HSE probe. The oligomer was coupled to magnetic particles coated with streptavidin, as described by the manufacturer. Seventy-five micrograms of NE from trophozoites were mixed with the magnetic particles in protein buffer, poly [d (I-C)] and poly-L-lysine. Then, NE was incubated at $4^{\circ} \mathrm{C}$ for $60 \mathrm{~min}$. After extensive washing, proteins bound to the particles were eluted with elution buffer containing $2 \mathrm{M} \mathrm{KCl}$. All of the fractions were analyzed by 10\% SDS-PAGE (Laemmli, 1970). The gels were silver stained or transferred to nitrocellulose membranes for western blotting assays. Purified fractions were added to DNA-protein binding reactions to perform EMSA, as described above. 


\section{Statistical Analysis}

All of the data are expressed as the means \pm SDs. IBM SPSS software, version 23, was used to compare all of the groups to each other. For all tests, $p<0.05$ was considered significant.

\section{RESULTS}

\section{Structural Characterization of the -170 to -111 bp of the EhPgp5 Gene Core Promoter}

Previously, a functional region of 59 bp ( -170 to $-111 \mathrm{bp})$ of the EhPgp5 gene promoter was involved in the induction of EhPgp5 gene expression (Nieto et al., 2005). To detect specific transcription elements within this region, we performed a bioinformatic search for the presence of consensus sequences of different transcription factors within the 59-bp EhPgp5 gene promoter region, using the TransFact database. The structural analysis of this sequence revealed the presence of putative consensus sequences for CdxA ( -170 to $-164 \mathrm{bp}$ ) and YY1 $(-163$ to $-153 \mathrm{bp})$ transcription factors and, interestingly, a HSE at -151 to -136 bp (Figure 1A).

\section{Functional Identification of the ERE in the Region from -170 to $-111 \mathrm{bp}$ of the EhPgp5 Gene Core Promoter}

To identify whether these cis-regulatory elements direct specific EhPgp5 gene expression in E. histolytica drug-sensitive $\left[\mathrm{A}_{(8)}\right]$ and drug-resistant $\left[\mathrm{C2}_{(20)}\right]$ clones grown in the presence of 8 and $20 \mu \mathrm{M}$ emetine, respectively, we performed a series of mutations and deletions within the $59 \mathrm{bp}$ region. Different constructs were generated, as described in the Materials and Methods section (Figures 1B,C). These plasmids contain internal deletions of CdxA, YY1, or HSE sequences.

Transfection assays of all constructs were performed in trophozoites from clones A and C2. In transfected trophozoites of both clones grown without emetine, no CAT activities were detected with any constructs, compared to the CAT activity developed by $\mathrm{pA} 5^{\prime} \mathrm{A} 3^{\prime} \mathrm{CAT}$ plasmid (Figure 2). However, when emetine was added to the culture medium after electroporation, we observed significantly higher CAT activities with all the constructs, similar to the activity shown by the EhPgp5 gene core promoter (p259Pgp5 plasmid) (Figure 2), except with the $\mathrm{p} \Delta 5$-HSEPgp 5 plasmid. No significant differences were observed in the CAT activities shown by $\triangle$ CdxAPgp5, $\triangle$ CdxA-YY1Pgp5, pmuCdxAPgp5, pmuYY1cPgp5, and pmuYY1gPgp5, suggesting that $\mathrm{CdXA}$ and YY1 putative consensus sequences were not involved in EhPgp5 gene transcriptional activation. In contrast, the construct $\mathrm{p} \Delta 5$-HSEPgp5 that does not contain six of 16 bases that form the putative HSE element (ataGAAatttTTCata) displayed significant CAT activity reductions of 80 and $78 \%$ in trophozoites from clones $\mathrm{A}_{[8]}$ and $\mathrm{C}_{[20]}$, respectively.

\section{The HSE Element Is Indispensable to Activating EhPgp5 Gene Transcription}

To demonstrate that the putative HSE ( -151 to $-136 \mathrm{bp}$ ) is responsible for activating EhPgp5 gene expression by emetine, we generated three new constructs introducing point mutations into the putative HSE. pmuHSEPgp5 contains three nucleotide replacements in the central inverted repeated GAA of HSE (ATAGAAATTTTTCATA $\rightarrow$ ATATCGATTTTTCATA); pmHSE-TTCPgp5 had three base changes in the inverted repeated TTC and its flanking bases (ATAGAAATTTTTCATA $\rightarrow$ ATAGAAATTAGATGAA), and in p-sinHSEPgp5, the HSE sequence was completely replaced (GACTGCTCGACGTGAC). We transfected these constructs into trophozoites from clones A and $\mathrm{C} 2$ and then cultured them in the absence or presence of 8 or $20 \mu \mathrm{M}$ emetine, respectively. The results showed that all of the constructs presented CAT activities in trophozoites from both clone cultures without emetine (Figure 3). However, a dramatic difference in expression was observed when emetine was added to the cultures, and the plasmid pmuHSEPgp5 presented higher CAT activity, similar to that shown by the p259Pgp5 minimal promoter (Figure 3). The activities observed were similar in both clones $\left[\mathrm{A}_{(8)}\right.$ and $\left.\mathrm{C}_{(20)}\right]$, suggesting that the changes introduced into the GAA sequence from the HSE did not affect the transcriptional activation. Interestingly, the plasmid pmHSE-TTCPgp5 presented a strong CAT activity reduction in trophozoites from both clones, suggesting that the second repeat of the HSE was indispensable to EhPgp5 gene expression. Moreover, when the HSE was eliminated, CAT reporter gene activity was not detected, either in trophozoites of clone $\mathrm{A}_{[8]}$ or in trophozoites of clone $\mathrm{C}_{2}$ [20] .

\section{The EhPgp5 HSE Is Recognized by Nuclear Proteins from E. histolytica Trophozoites from Sensitive and Resistant Clones}

As a second approach to gaining insight into the role of HSEs in the promoter activity of the EhPgp5 gene, we analyzed DNAprotein interactions using gel shift and competition assays. Gel electrophoretic mobility shift assays were performed to obtain evidence of nuclear protein binding to the putative HSE. Double-stranded synthetic oligonucleotides containing the EhPgp 5 HSE were incubated with NE from clones A, $\mathrm{A}_{[8]}, \mathrm{C} 2$, and $\mathrm{C}_{[20]}$. Additionally, oligonucleotides containing the wildtype consensus HSE and the HSEm mutated at the repeated GAA and the region of $34 \mathrm{bp}$ of the EhPgp5 promoter from -170 to $-136 \mathrm{bp}$, which contains the CdxA, YY1, and HSE sequences, were used as specific competitors. As demonstrated in Figures $\mathbf{4 A}, \mathbf{B}$, the HSE was specifically recognized by nuclear proteins from E. histolytica clones grown in the presence or absence of emetine, forming one DNA-protein complex that had identical electrophoretic mobility using NE from both clones. Interestingly, the intensity of the complex was enhanced when the DNA probe was incubated with NE from the trophozoites from clones $\mathrm{A}_{[8]}$ and $\mathrm{C}_{[20]}$ (Figures $4 \mathbf{A}-\mathbf{D}$, lanes 2 and 7). Competition assays showed that formation of the complex with the HSE probe was efficiently blocked by the wild-type HSE and the S34 oligonucleotides when a 150-fold molar excess was used (Figures 4A-E, lanes 3, 5, 8, and 10) but not with the HSEm, for which the DNA-protein complexes only diminished (Figures 4A-E, lanes 4 and 9), suggesting that the DNA-protein interaction was partially affected by changing the GAA repeated 
A
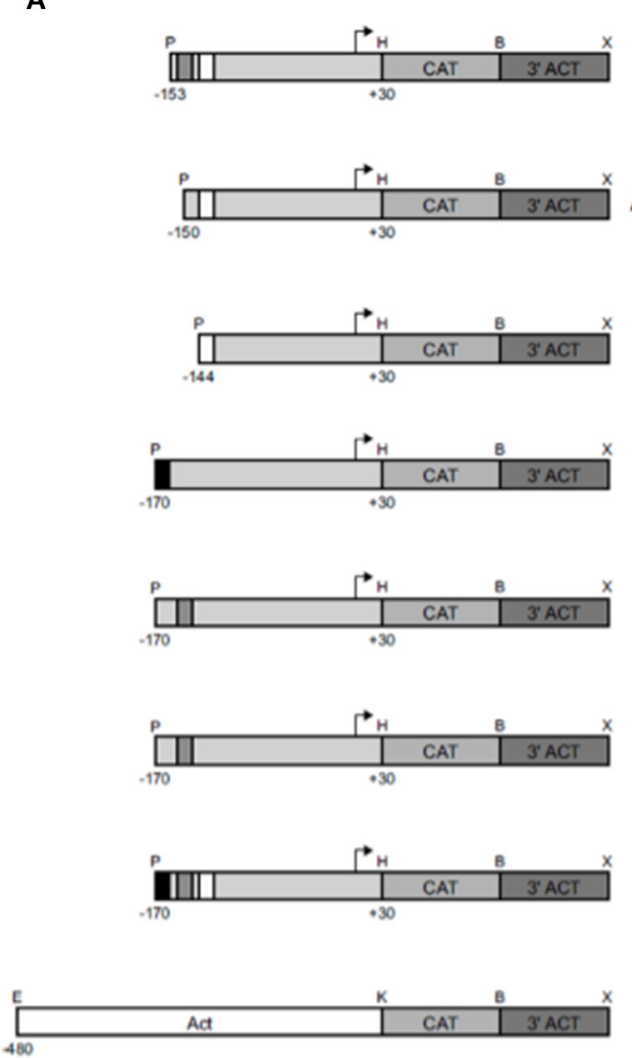

$\triangle \mathrm{CdXA-YY1Pgp5}$

pmuCdxAPgp5

p259Pgp5

B

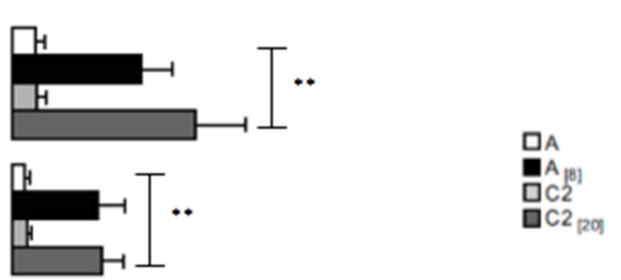

$\triangle 5$-HSEPgp5

pmuYY1cPgp5

pmuYY1gPgp5

PA5'A3'CAT

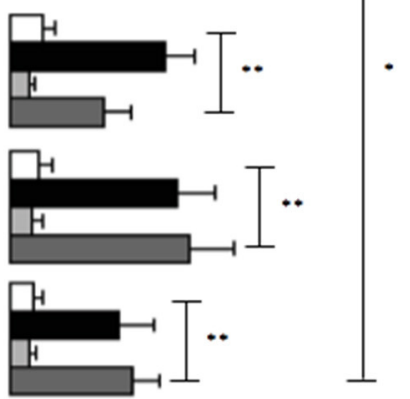

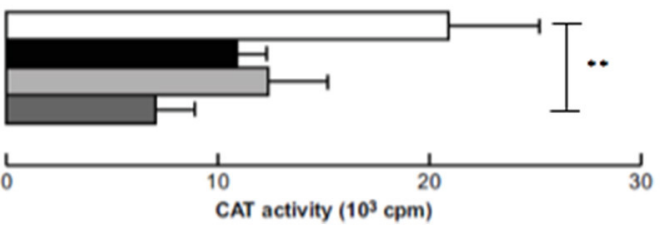

FIGURE 2 | Functional identification of the ERE in the region from -170 to -111 bp of the EhPgp5 gene core promoter. (A) Schematic representation of the constructs used for the transfection assays. All of the plasmids contain the CAT reporter gene and the $3^{\prime}$-flanking actin region ( $3^{\prime}$ ACT). Arrows, transcription initiation sites. P, Pstl; H, Hindlll; B, BamHI; X, Xhol; E, EcoRl; K, Kpnl. CdXA, YY1, and HSE motifs are in black, gray and white boxes, respectively. (B) Bars show the average of CAT activity (cpm) of the transfected plasmids obtained by the two-phase diffusion assays $\pm S D$, representative of three independent experiments performed in duplicate $\left({ }^{*} p<0.05 ;{ }^{* *} p<0.001\right)$. The background given by the trophozoites transfected with pBSCAT-ACT plasmid was subtracted in all of the experiments. The efficiency of the transfection assays was monitored by the activities given by the $\mathrm{PA5}{ }^{\prime} \mathrm{A} 3^{\prime} \mathrm{CAT}$ plasmid.

sequence. However, this change did not interfere with the EhPgp5 promoter activity (Figures 4 A,B). In contrast, when poly [d(IC)] was used as a non-specific competitor (350-fold molar excess), the DNA-protein complex formation was not affected (Figures 4A-D, lanes 6 and 11).

\section{Molecular Weights of the Nuclear Proteins Binding to the EhPgp5 HSE}

To identify the nuclear proteins binding to the EhPgp5 HSE, we performed UV-crosslinking assays after gel shift. Two main proteins of 51 and $34 \mathrm{kDa}$ after correction for the bound probe (61 and $44 \mathrm{kDa}$ ) were found in both clones incubated with or without emetine (Figure 5). The HSE-protein interactions were specific due to complex formation being prevented by a 150 fold molar excess of cold oligonucleotide (lane 5), while binding proteins were not inhibited using the unspecific competitor poly [d (I-C)] (lane 6), indicating the specificity of the complexes. The bands obtained using the NE trophozoites from both clones grown in the presence of emetine (Figures $\mathbf{5 A}, \mathbf{C}, \mathbf{E}, \mathbf{F}$ ), were more intense than the bands obtained using the NE trophozoites from both clones grown in the absence of emetine (Figures 5B,D-F).

\section{Putative Heat Shock Transcription Factor Binds to the EhPgp5 HSE}

To identify the proteins interacting with the EhPgp5 HSE, we searched for putative heat shock transcription factors (HSTF) by western blot assays of the UV-crosslinked complexes from trophozoites of clones $\mathrm{A}, \mathrm{A}_{[8]}, \mathrm{C} 2$, and $\mathrm{C}_{[20]}$ using the human heterologous antibody anti-HSF1. As shown in Figure 5G, a band of $51 \mathrm{kDa}$ was detected after correction for the bound probe from the DNA-protein complex formed with the HSE element. The band was stronger (20\%) in $\mathrm{C}_{[20]}$, trophozoites (Figure 5H). In trophozoites from both clones grown without emetine, a very slight signal was detected (data not show). 


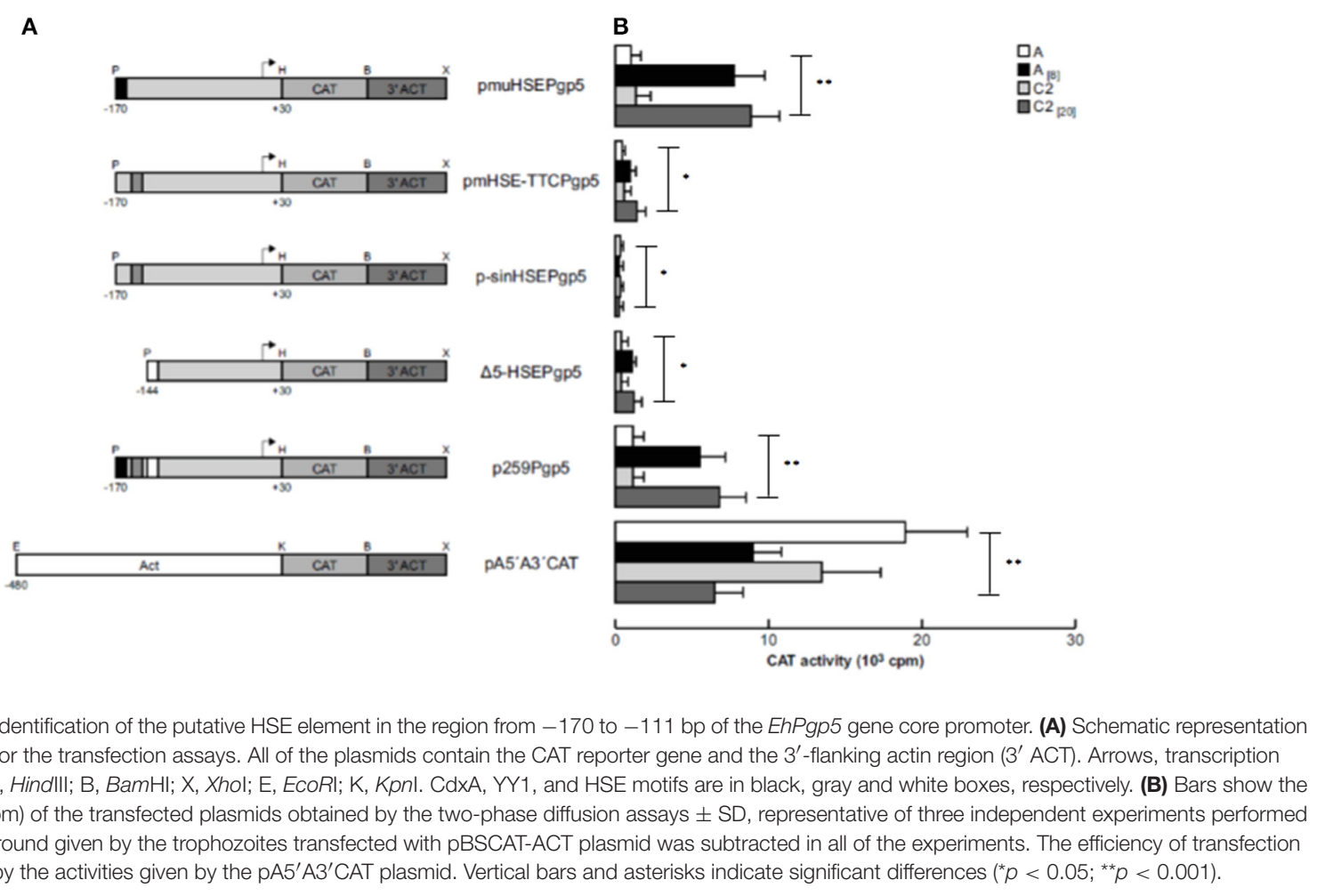

\section{Partial Purification of the Proteins Binding to the EhPgp5 HSE}

We performed partial purification of proteins that bind to the HSE using the DNA-binding protein purification kit from Roche Molecular Biochemical (Roche, CA, USA), NE from trophozoites of clones $\mathrm{A}_{[8]}$ and $\mathrm{C}_{[20]}$ and a concatamerized oligonucleotide containing the HSE. Two main and defined enrichment purified proteins of $\sim 94$ and $66 \mathrm{kDa}$, respectively, were detected on a silver-stained SDS-polyacrylamide gel in NE from trophozoites of clone $A_{[8]}$, (Figure 6A, lane 3), while two proteins of 62 and $51 \mathrm{kDa}$ were purified from the NE from the trophozoites of clone $\mathrm{C}_{[20]}$ (Figure 6D, lane 3). To determine whether purified proteins were also detected by the HSTF1 heterologous antibody, we performed western blot assays. The results showed that both pairs of proteins, 94 and $66 \mathrm{kDa}$ and 62 and $51 \mathrm{kDa}$ from $\mathrm{A}_{[8]}$ and $\mathrm{C}_{[20]}$ trophozoites, respectively, were recognized by the human anti-HSTF1 (Figures 6B,E). These results supported the idea that the proteins that binding to the EhPgp5 HSE could be putative heat shock like transcription factors.

Furthermore, the semipurified proteins from both clones were used to determine whether these proteins could bind to the HSE sequence. As shown in Figures $\mathbf{6 C , F , G , H}$ (lane $2)$, two specific DNA-protein complexes were observed with the semipurified proteins of clones $\mathrm{A}_{[8]}$ and $\mathrm{C}_{[20]}$. The complexes were highly specific due to being completely inhibited by a 150 -fold molar excess of the same unlabeled wild-type HSE and S34 oligonucleotides (lanes 3 and 5), and 350-fold molar excess of poly $[\mathrm{d}(\mathrm{I}-\mathrm{C})]$ did not affect complex formation (lane 6). Interestingly, the HSEm did not affect complex formation (Figures 6C,F-H lane $4)$.

\section{DISCUSSION}

The EhPgp5 gene and its encoded P-glycoprotein (EhPGP5) have functional relevance in different mechanisms of E. histolytica parasites. On the one hand, the antisense inhibition of gene expression enhances the PCD of trophozoites in the presence of G418; on the other hand, gene overexpression alters the chloridedependent currents and confers drug resistance to emetine (Pérez et al., 1998; Bañuelos et al., 2002; Delgadillo et al., 2002; Medel Flores et al., 2013).

Therefore, due to the relevance of EhPGP5 for different cellular processes, its transcription must be finely regulated. To determine the molecular effectors up-regulating EhPgp5 gene expression, our group performed the structural and functional characterization of EhPgp5 gene promoter (Pérez et al., 1998) in trophozoites growth in the absence and presence of emetine, delimiting a 59 bp region at the position from -170 to $-111 \mathrm{bp}$, in which putative EREs were found (Nieto et al., 2005).

Here, we investigated for the first time the functional roles of motifs found in promoter activity. Consensus DNAbinding sequences for different transcription factors are well conserved throughout evolution, and different databases of transcription factors and promoters have been established to develop algorithms, as well as computer methods to predict sequence target sites for specific DNA-binding proteins (Boeva, 


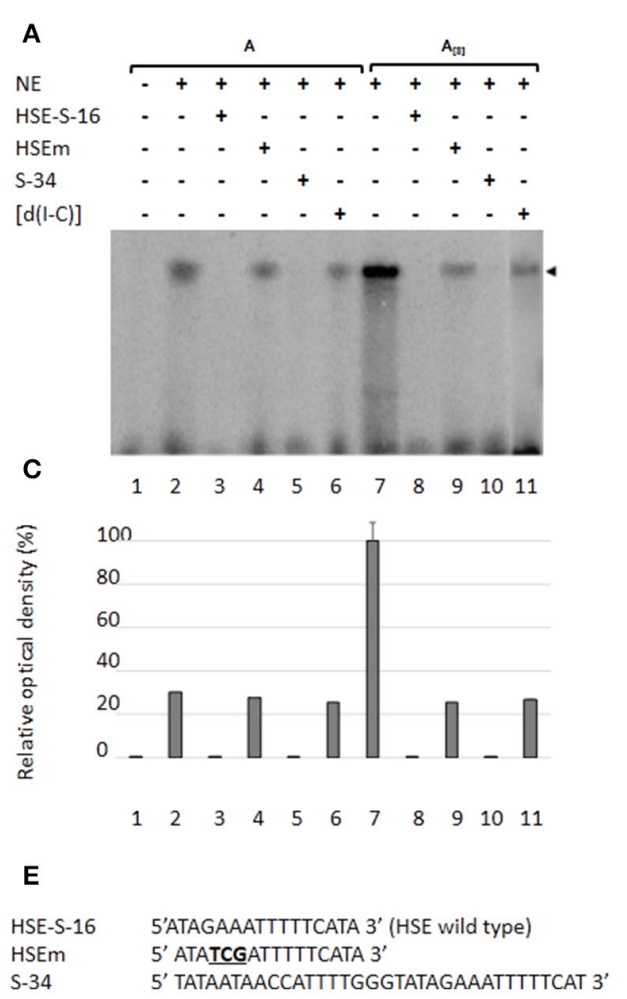

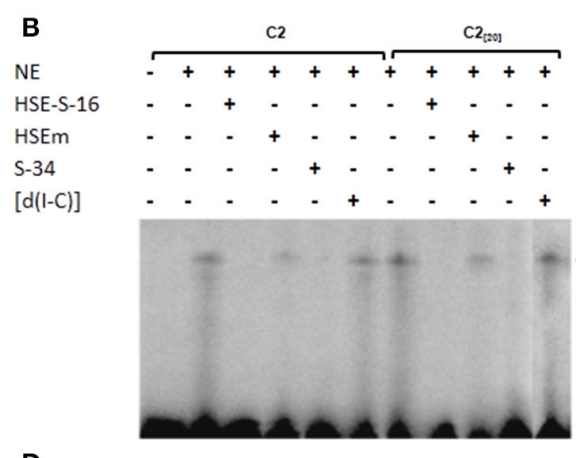

D

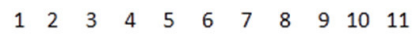

$\frac{3}{8}$
$\frac{2}{5}$
$\frac{0}{0}$
$\frac{0}{8}$
$\frac{8}{0}$
0
$\frac{0}{0}$
$\frac{0}{0}$
$\frac{0}{2}$

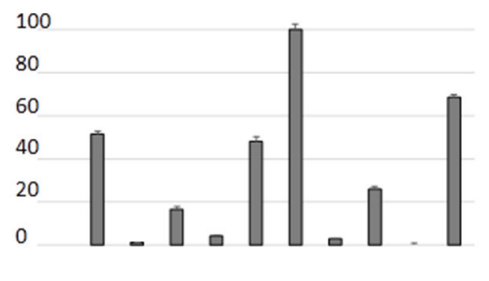

$\begin{array}{lllllllllll}1 & 2 & 3 & 4 & 5 & 6 & 7 & 8 & 9 & 10 & 11\end{array}$

FIGURE 4 | Nuclear protein binding with the putative HSE element of the EhPgp5 gene core promoter. Gel shift assays were performed with $20 \mu \mathrm{g}$ of NE from clones: (A) A and $\mathrm{A}_{[8]}$, (B) $\mathrm{C} 2$ and $\mathrm{C}_{[20]}, 1 \mathrm{ng}$ of [ $\left.\gamma^{-}{ }^{32} \mathrm{P}\right]$-radiolabeled double-stranded fragment of different unlabeled oligonucleotides (150-fold molar excess). Lane 1, free probe; lanes 2 and 7, no competitor; lanes 3 and 8 specific competitor unlabeled straight (150-fold molar excess); lanes 4 and 9 , specific competitor with the HSE mutated at the repeated GAA; lanes 5 and 10, specific competitor containing the CdXA, YY1, and HSE consensus sequences; lanes 6 and 11 unspecific competitor (350-fold molar excess of poly [d(I-C)]). Arrowheads indicate the specific complexes formed. (C,D) Densitometric analysis of DNA-binding interaction with NE from clones A and $A_{[8]}$ and $\mathrm{C} 2$ and $\mathrm{C}_{[20]}$, respectively. (E) Sequence of the EhPgp5 HSE used as a probe (HSE-S-16) and the competitors (HSEm and S-34). Mutations are underlined and bolded in black. Data presented in this figure are representative of three independent experiments.

2016). The bioinformatic screening revealed three consensus sequences for CdxA, YY1, and HSE, recognized by the CdxA, Ying Yang 1 (YY1), and HSTF proteins, respectively (Perisic et al., 1989; Shi et al., 1991; Margalit et al., 1993).

In E. histolytica, seven putative HSEs located in EhrabB, three in Ehhsp100 and four in Ehmlbp gene promoter have been reported (Bernes et al., 2005; Romero-Díaz et al., 2007; Katz et al., 2012). Functional CAT assays driven by EhrabB promoter demonstrated that CAT activity increased by two times when trophozoites were exposed to heat shock stress $\left(42^{\circ} \mathrm{C}\right)$ (Romero-Díaz et al., 2007). Deletion of HSEs from Ehmlbp gene promoter down-regulated CAT reporter gene expression in trophozoites exposed to heat shock (Katz et al., 2012), while the activity of the HSEs present in Ehhsp100 gene promoter has not yet been studied. Comparison of the HSE from the EhPgp5 gene promoter with those reported in E. histolytica showed greater similarity with the HSEs of the Ehhsp100 gene promoter. Both sequences were formed by two motifs; however, the orientation of the EhPgp5 HSE (ATAGAAATTTTTCATA) is head-tail (GAA and TTC), while that of the Ehhsp100 is headhead (AAGGAACTTGAAGAA), containing a gap of four and three bases between them, respectively (Bernes et al., 2005). In contrast, Tchénio et al. (2006) that osteosarcoma cells became doxorubicin resistant by overexpression of the MDR1 gene, induced by the HSE. These results together supported the idea that HSE within the EhPgp5 gene promoter is relevant for its expression in trophozoite culture under emetine drug pressure, which is a stress situation. Functional analyses of the HSE (nGAAnnTTCn) in other organisms have demonstrated that the GAA and TTC motifs contain indispensable bases for DNA-protein interactions and consequently for promoter activation (Enoki and Sakurai, 2011). Mutations or deletions of these motifs decreased or abolished the promoter activity of the RPN4 and PDR3 genes in Saccharomyces cerevisiae and $B n G o l S 1$ in plant cells in a similar manner to that we observed for the EhPgp5 HSE (Hahn et al., 2006; Lang et al., 2017). We demonstrated here that CAT activity was abolished by complete HSE substitution or by TTC (GAT) mutation, strongly supporting that emetine increases the activity of the EhPgp5 gene promoter via HSE.

Using DNA-protein interactions, western blots from crosslinked and semipurified proteins employing heterologous HSTF antibodies indicated that HSE interacts with an HSTF-like factor present in both sensitive and resistant trophozoites; 


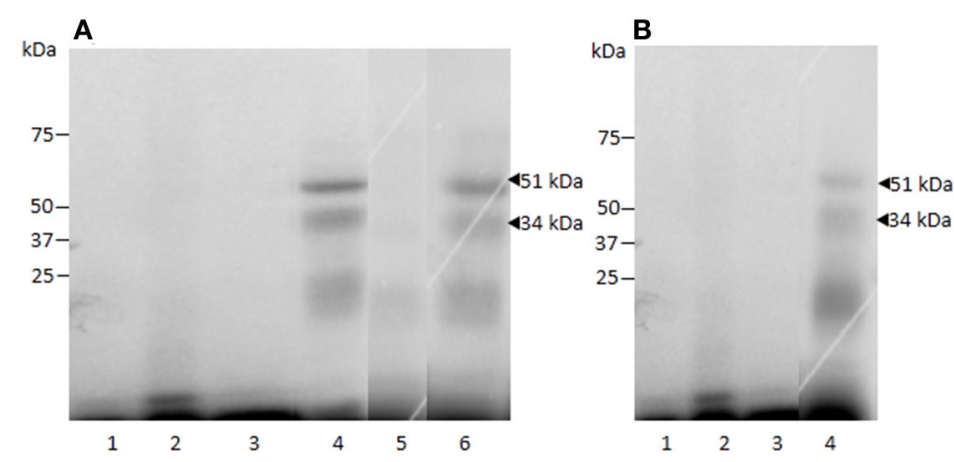

C

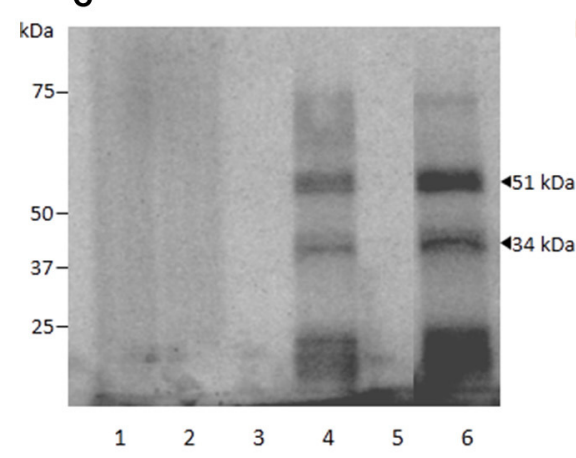

D

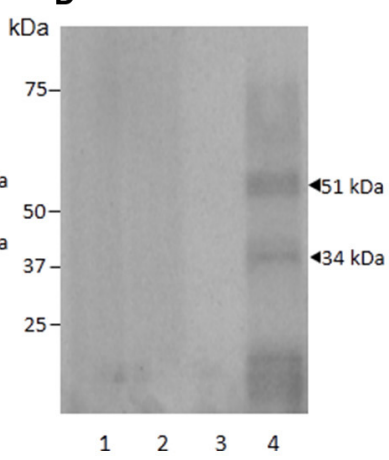

E

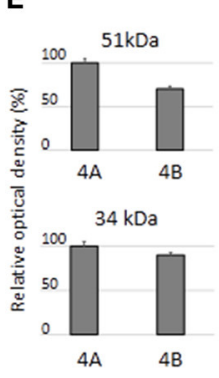

\section{G}

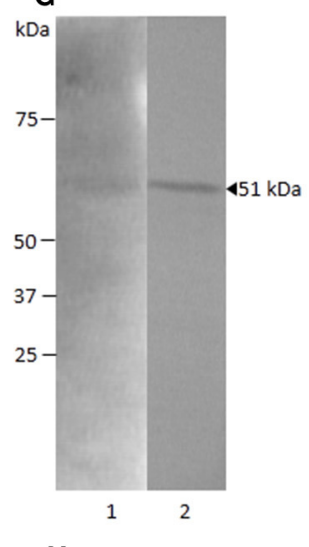

H

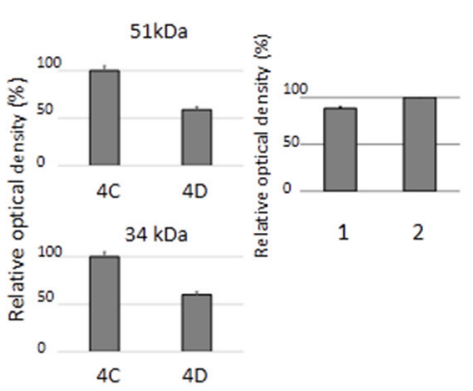

FIGURE 5 | Molecular weight of the nuclear proteins binding to the EhPgp5 HSE and their immunorelation to human HSF. UV-crosslinking analyses after EMSA in A and $\mathrm{C} 2$ clone grown in the presence $\mathbf{( A , C )}$ or in the absence $\mathbf{( B , D )}$ of emetine. One hundred micrograms of NE from clones A $(\mathbf{A}, \mathbf{B})$ and $\mathrm{C} 2(\mathbf{C}, \mathbf{D})$ trophozoites were UV cross-linked to $5 \mathrm{ng}$ of the $\gamma^{32} \mathrm{P}$-ATP radiolabeled HSE probe for $10 \mathrm{~min}$ at $4^{\circ} \mathrm{C}$, and DNA-protein complexes were electrophoresed through $15 \%$ SDS-PAGE, followed by exposure to X-ray film. Lane 1, UV untreated HSE probe; lane 2, UV irradiation of HSE probe; lane 3, UV untreated complete binding reaction; lane 4, UV treatment of complete binding reaction; lane 5, probe (150-fold molar excess); lane 6 , unspecific competitor poly [d(I-C)]. Arrowheads, DNA-protein complexes after correction for the bound probe. Relative densitometry of each protein in clones $\mathrm{A}_{[8]}$ and $\mathrm{A}(\mathbf{E})$ and $\mathrm{C}_{[20]}$ and $\mathrm{C} 2$ (F). (G) Western blot assay of UV cross-linked DNA-protein complexes of clones $\mathrm{A}_{[8]}$ and $\mathrm{C}_{\text {[20] }}$ using heterologous antibodies to anti-HSF1 from humans with their corresponding densitometric values. (H) Lane 1 , clone $\mathrm{A}_{[8]}$; and lane 2, clone $\mathrm{C}_{[20]}$. All assays were performed on three different occasions.

however, functional CAT assays demonstrated that the promoter was active only in the presence of emetine, suggesting that binding of HSTF-like factor is not sufficient to drive promoter activity. Several pieces of evidence from other systems have shown that HSTF factors present a multistep activation mechanism (trimerization, phosphorylation, and translocation to nucleus) to activate gene expression (Sorger and Pelham, 1988; Høj and Jakobsen, 1994; Sandqvist et al., 2009). These factors are activated in the presence of stress induced by heat, oxidative stress, heavy metals, bacterial toxins, and drugs between others (Høj and Jakobsen, 1994; Akerfelt et al., 2007). In amoebas, it was reported that the HSE from Ehhsp100 promoter was recognized by a $37 \mathrm{kDa}$ protein when the trophozoites were exposed to heat shock (Bernes et al., 2005), while a $25 \mathrm{kDa}$ protein bound to the HSE in Ehmlbp promoter also under heat shock (Katz et al., 2012).

Different experimental procedures performed here showed that HSE interacts with 94,66 , and $51 \mathrm{kDa}$ proteins in sensitive trophozoites, while in resistant ones, HSE interacts with 62 and $51 \mathrm{kDa}$, both recognized by HSTF antibodies.
Differences found in the molecular weights of EhHSTF-like proteins interacting with the HSE in sensitive and resistant clones could be due to: (i) translational modifications; (ii) formation of homodimers or homotrimers; or (iii) interactions with other proteins, for example, molecular weight changes in human HSFs by different posttranslational modifications, mainly phosphorylation (Sorger et al., 1987; Larson et al., 1988; Baler et al., 1993; Sarge et al., 1993). These factors are able to trimerize or interact with different proteins, such as CHIP (Cterminus of HSP70-interacting protein) (Murata et al., 2003), DDL-1 and DDL-2, forming a complex that stabilizes HSF1 monomers (Chiang et al., 2012), or with HSP70 and HSP90 to keep HSTF1 in an inactive state preventing trimerization (Zou et al., 1998) or even more perhaps interacting with other human HSFs (HSF1, HSF2, HSF3, and HSF4) (Rabdiran et al., 1991; Schuetz et al., 1991; Nakai et al., 1997). In this parasite, eight Hsps (101, 100, 90, 70, 60, 40, 20, and 10) have been identified, and some of them have been characterized, showing their participation in heat shock stress (Bernes et al., 2005; Ximénez et al., 2017). These results suggest that amoebas 

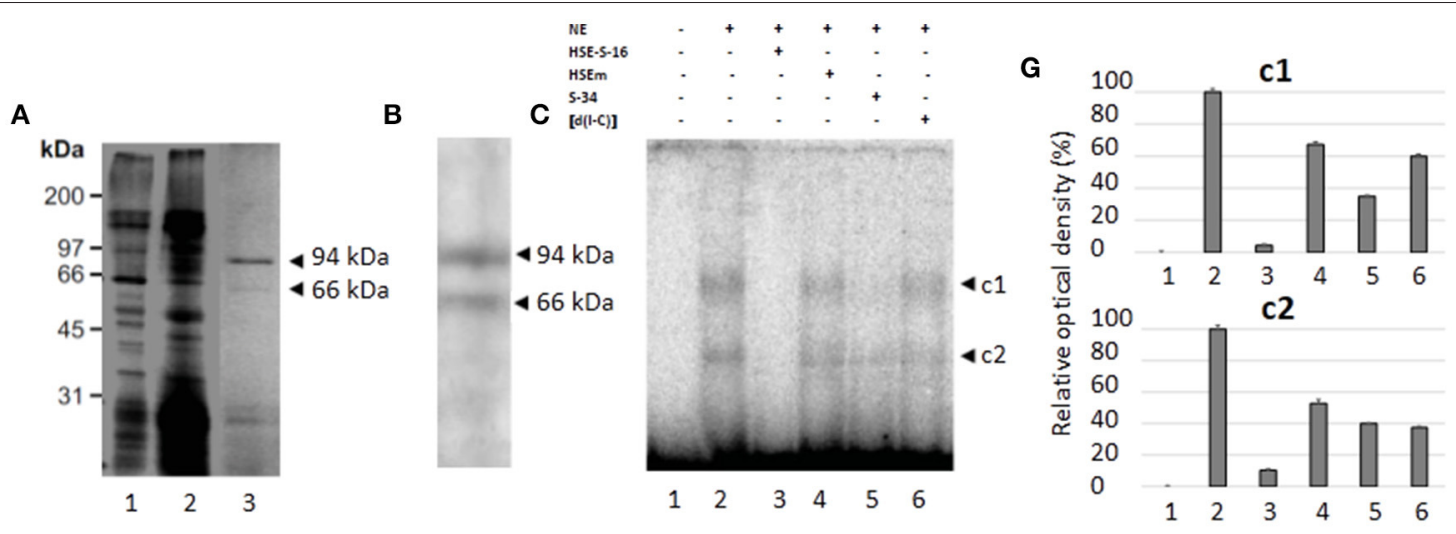

H
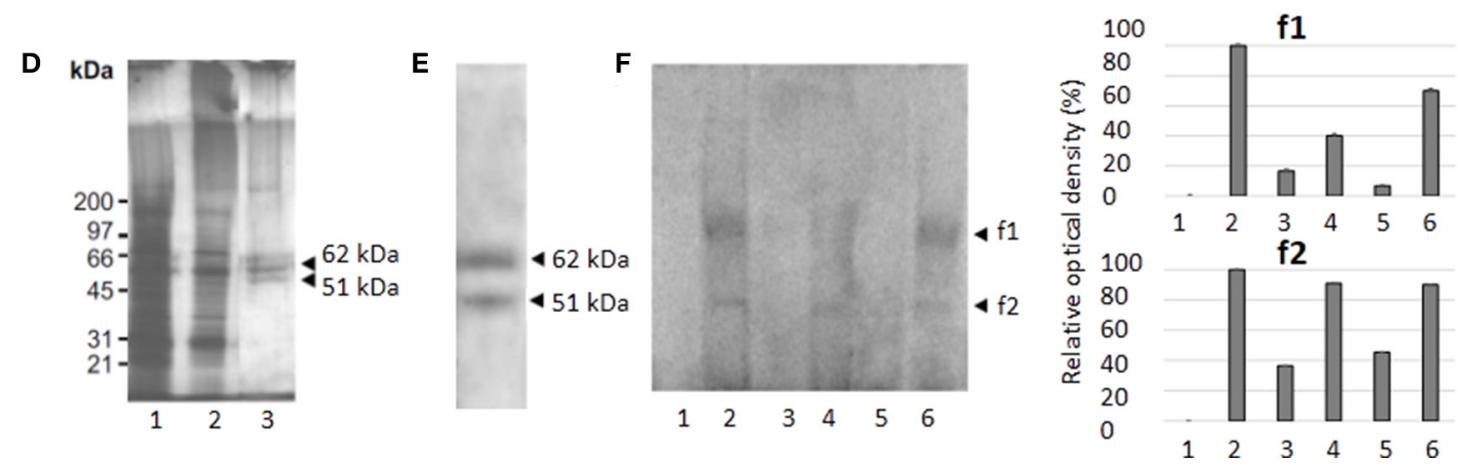

FIGURE 6 | Purification, immunodetection, and DNA-interaction of the nuclear proteins that bind to the HSE element (A,D). 10\% SDS-PAGE of protein fractions obtained from the purification protocol of NE from clones $\mathrm{A}_{[8]}$ and $\mathrm{C}_{[20]}$, respectively. Lane 1, NE (5 $\left.\mu \mathrm{g}\right)$; lane 2, non-retained fraction; and lane 3, partially purified fraction. (B,E) Western blot analysis of fractions obtained from the purification protocol of $\mathrm{NE}$ of clones $\mathrm{A}_{[8]}$ and $\mathrm{C}_{[20]}$, respectively. Arrowheads, silver stained polypeptides detected by antibodies against HSF1 from humans. (C,F) EMSA using $\left[\gamma^{-}{ }^{32} \mathrm{P}\right]-$ ATP radiolabeled HSE probe and partially purified fraction from clones $\mathrm{A}_{[8]}$ and $\mathrm{C}_{[20]}$, respectively. Lane 1, free probe; lane 2, no competitor; lane 3, specific competitor unlabeled straight (150-fold molar excess); lane 4, specific competitor with the HSE mutated; lane 5, specific competitor containing the CdXA, YY1, and HSE consensus sequences; lane 6, unspecific competitor (350-fold molar excess of poly[d(I-C)]]). Arrowheads, specific complexes formed. $(\mathbf{G}, \mathbf{H})$ Relative amounts of DNA binding protein complexes with partial purification proteins of clones A[8] and C2[20], respectively. Each bar indicates the mean \pm SE. Data presented in this figure are representative of three independent experiments.

might contain an HSTF demonstrated in other organisms, which is responsible for controlling the expression of the $h s p$ genes (Driedonks et al., 2015). In the literature, it has been described that HSF is a master regulator of stress-responsive genes among organisms as distantly related as bacteria and humans (Guertin et al., 2010). Moreover, in the E. histolytica genome, seven putative HSTFs are present that could interact with the HSE of the EhPgp5 gene promoter in trophozoites grown in the presence of emetine (Bernes et al., 2005; Loftus et al., 2005; Macías-Arguelles, in preparation). However, we do not know which of the seven factors is being expressed and is regulating EhPgp5 gene expression. HSFs are characterized by their ability to bind to the HSE; but, in organisms containing different HSFs, such as humans, mice, and chickens, it has been described that each is able to regulate different genes (Driedonks et al., 2015).

The findings presented here provide evidence of the participation of a novel HSE that requires a putative HSTFlike factor(s) to regulate the transcriptional activation of the multidrug-resistant EhPgp5 gene in trophozoites exposed to emetine, as has been reported in human MDR1 multidrugresistance gene. However, the underlying mechanisms explaining how a putative EhHSTF recognizes and binds to the HSE, how emetine activates the EhPgp5 promoter via EhHSTF, and which of the seven EhHSTFs binds to the HSE remain to be discovered.

\section{AUTHOR CONTRIBUTIONS}

AN: Data acquisition and analysis or for the work. DP: interpretation of data and revision of intellectual content. EO: Revision of intellectual content. VS: Draft the work and revision of intellectual content. CG: Design of the work and revision of intellectual content.

\section{ACKNOWLEDGMENTS}

This work was supported by the Consejo Nacional de Ciencia y Tecnología (CONACyT-39986) and Instituto Politécnico Nacional (Secretaría de Investigación y Posgrado). We would like to thank Alfredo Padilla for his help with the artwork. 


\section{REFERENCES}

Akerfelt, M., Trouillet, D., Mezger, V., and Sistonen, L. (2007). Heat shock factors at a crossroad between stress and development. Ann. N. Y. Acad. Sci. 1113, 15-27. doi: 10.1196/annals.1391.005

Ausubel, F. M., Brent, R., Kingston, R. E., Moore, D. D., Seidman, J. G., Smith, J. A., et al. (1994). Current Protocols in Molecular Biology. New York, NY: John Wiley and Sons.

Baler, R., Dahl, G., and Voellmy, R. (1993). Activation of human heat shock genes is accompanied by oligomerization, modification, and rapid translocation of heat shock transcription factor HSF1. Mol. Cell. Biol. 13, 2486-2496 doi: 10.1128/MCB.13.4.2486

Bañuelos, C., Orozco, E., Gómez, C., González, A., Medel, O., Mendoza, L., et al. (2002). "Cellular location and function of the P-glycoproteins (EhPgps)" in Entamoeba histolytica Multidrug-Resistant Trophozoites. Microb. Drug Resist. 8, 291-300. doi: 10.1089/10766290260469552

Bernes, S., Siman-Tov, R., and Ankri, S. (2005). Epigenetic and classical activation o Entamoeba histolytica heat shock protein 100 (EHsp100) expression. FEBS Lett. 579, 6395-6402. doi: 10.1016/j.febslet.2005.09.101

Boeva, V. (2016). Analysis of genomic sequence motifs for deciphering transcription factor binding and transcriptional regulation in eukaryotic cells. Front. Genet. 7:24. doi: 10.3389/fgene.2016.00024

Bradford, M. M. (1976). A rapid and sensitive method for the quantitation of microgram quantities of protein utilizing the principle of protein-dye binding. Anal. Biochem. 72, 248-254. doi: 10.1016/0003-2697(76)90527-3

Chiang, W. C., Ching, T. T., Lee, H. C., Mousigian, C., and Hsu, A. L. (2012). HSF1 regulators DDL-1/2 link insulin-like signaling to heat-shock responses and modulation of longevity. Cell 148, 322-334. doi: 10.1016/j.cell.2011.12.019

Chin, J. E., Soffir, R., Noonan, K. E., Choi, K., and Roninson, I. B. (1989). Structure and expression of the human MDR (P-glycoprotein) gene family. Mol. Cell. Biol. 9, 3808-3820 doi: 10.1128/MCB.9.9.3808

Cui, Y. J., Cheng, X., Weaver, Y. M., and Klaassen, C. D. (2009). Tissue distribution, gender-divergent expression, ontogeny, and chemical induction of multidrug resistance transporter genes (Mdrla, Mdr1b, Mdr2) in mice. Drug Metab. Dispos. 37, 203-210. doi: 10.1124/dmd.108.023721

Delgadillo, D. M., Pérez, D. G., Gómez, C., Ponce, A., Paz, F., Bañuelos, C., et al. (2002). The Entamoeba histolytica EhPgp5 (MDR-like) protein induces swelling of the trophozoites and alters chloride-dependent currents in Xenopus laevis oocytes. Microb. Drug Resist. 8, 15-26. doi: 10.1089/10766290252913719

Descoteaux, S., Ayala, P., Samuelson, J., and Orozco, E. (1995). Increase in mRNA of multiple Eh pgp genes encoding P-glycoprotein homologues in emetine-resistant Entamoeba histolytica parasites. Gene 164, 179-184 doi: 10.1016/0378-1119(95)00533-C

Diamond, L. S., Harlow, D. R., and Cunnick, C. C. (1978). A new medium for the axenic cultivation of Entamoeba histolytica and other Entamoeba. Trans. R. Soc. Trop. Med. Hyg. 72, 431-432 doi: 10.1016/0035-9203(78)90144-X

Driedonks, N., Xu, J., Peters, J. L., Park, S., and Rieu, I. (2015). Multilevel interactions between heat shock factors, heat shock proteins, and the redox system regulate acclimation to heat. Front. Plant Sci. 6:999. doi: 10.3389/fpls.2015.00999

Enoki, Y., and Sakurai, H. (2011). Diversity in DNA recognition by heat shock transcription factors (HSFs) from model organisms. FEBS Lett. 585, 1293-1298. doi: 10.1016/j.febslet.2011.04.014

Gómez, C., Pérez, D. G., López-Bayghen, E., and Orozco, E. (1998). Transcriptional analysis of the EhPgp1 promoter of Entamoeba histolytica multidrug-resistant mutant. J. Biol. Chem.. 273, 7277-7284. doi: 10.1074/jbc.273.13.7277

Gómez, M. D., Pérez, D. G., Ayala, P., Samuelson, J., and Orozco, E. (1996). Physiology and molecular biology of multidrug resistance in Entamoeba histolytica. Arch. Med. Res. 27, 421-425

Grogl, M., Martin, R. K., Oduola, A. M., Milhous, W. K., and Kyle, D. E. (1991). Characteristics of multidrug resistance in Plasmodium and Leishmania: detection of P-glycoprotein-like components. Am. J. Trop. Med. Hyg. 45, 98-111 doi: 10.4269/ajtmh.1991.45.98

Guertin, M. J., Petesch, S. J., Zobeck, K. L., Min, I. M., and Lis, J. T. (2010). Drosophila heat shock system as a general model to investigate transcriptional regulation. Cold Spring Harb. Symp. Quant. Biol. 75, 1-9. doi: 10.1101/sqb.2010.75.039
Hahn, J. S., Neef, D. W., and Thiele, D. J. (2006). A stress regulatory network for co-ordinated activation of proteasome expression mediated by yeast heat shock transcription factor. Mol. Microbiol. 60, 240-251. doi: 10.1111/j.1365-2958.2006.05097.x

Høj, A., and Jakobsen, B. K. (1994). A short element required for turning off heat shock transcription factor: evidence that phosphorylation enhances deactivation. EMBO J. 13, 2617-2624.

Juranka, P. F., Zastawny, R. L., and Ling, V. (1989). P-glycoprotein: multidrugresistance and a superfamily of membrane-associated transport proteins. FASEB J. 14, 2583-2592.

Katz, S., Kushnir, O., Tovy, A., Siman Tov, R., and Ankri, S. (2012). The Entamoeba histolytica methylated LINE-binding protein EhMLBP provides protection against protein heat shock. Cell. Microbiol. 14, 58-70. doi: $10.1111 /$ j.1462-5822.2011.01697.x

Laemmli, U. K. (1970). Cleavage of structural proteins during the assembly of the head of bacteriophage T4. Nature 227, 680-685 doi: 10.1038/227680a0

Lang, S., Lui, X., Xue, H., Li, X., and Wang, X. (2017). Functional characterization of BnHSFA4a as a heat shock transcription factor in controlling the reestablishment of desiccation tolerance in seeds. J. Exp. Bot. 68, 2361-2375. doi: 10.1093/jxb/erx097

Larson, J. S., Schuetz, T. J., and Kingston, R. E. (1988). Activation in vitro of sequence-specific DNA binding by a human regulatory factor. Nature 335, 372-375. doi: 10.1038/335372a0

Loftus, B., Anderson, I., Davies, R., Alsmark, U. C., Samuelson, J., Amedeo, P., et al. (2005). The genome of the protist parasite Entamoeba histolytica. Nature 433, 865-868. doi: 10.1038/nature03291

López-Camarillo, C., Luna-Arias, J. P., Marchat, L. A., and Orozco, E. (2003). EhPgp5 MRNA stability is a regulatory event in the Entamoeba histolytica multidrug resistance phenotype. J. Biol. Chem. 278, 11273-11280. doi: 10.1074/jbc.M211757200

Margalit, Y., Yarus, S., Shapira, E., Gruenbaum, Y., and Fainsod, A. (1993). Isolation and characterization of target sequences of the chicken CdxA homeobox gene. Nucleic Acids Res. 21, 4915-4922. doi: 10.1093/nar/21.21.4915

Matys, V., Kel-Margoulis, O. V., Fricke, E., Liebich, I., Land, S., BarreDirrie, A., et al. (2006). TRANSFAC and its module TRANSCompel: transcriptional gene regulation in eukaryotes. Nucleic Acids Res. 34, D108D110. doi: 10.1093/nar/gkj143

Medel Flores, O., Gómez García, C., Sánchez Monroy, V., Villalba Magadaleno, J. D., Nader García, E., and Pérez Ishiwara, D. G. (2013). Entamoeba histolytica P-glycoprotein (EhPgp) inhibition, induce trophozoite acidification and enhance programmed cell death. Exp. Parasitol. 135, 532-540. doi: 10.1016/j.exppara.2013.08.017

Mickley, L. A., Bates, S. E., Richert, N. D., Currier, S., Tanaka, S., Foss, F., et al. (1989). Modulation of the expression of a multidrug resistance gene (mdr-1/P-glycoprotein) by differentiating agents. J. Biol. Chem. 264, 18031-18040.

Moons, A. (2003). Ospdr9, which encodes a PDR-type ABC transporter, is induced by heavy metals, hypoxic stress and redox perturbations in rice roots. FEBS Lett. 553, 370-376. doi: 10.1016/S0014-5793(03)01060-3

Murata, S., Chiba, T., and Tanaka, K. (2003). CHIP: a quality-control E3 ligase collaborating with molecular chaperones. Int. J. Biochem. Cell Biol. 35, 572-578. doi: 10.1016/S1357-2725(02)00394-1

Nakai, A., Tanabe, M., Kawazoe, Y., Inazawa, J., Morimoto, R. I., and Nagata, K. (1997). HSF4, a new member of the human heat shock factor family which lacks properties of a transcriptional activator. Mol. Cell. Biol. 17, 469-481. doi: 10.1128/MCB.17.1.469

Nickel, R., and Tannich, E. (1994). Transfection and transient expression of chloramphenicol acetyltransferase gene in the protozoan parasite Entamoeba histolytica. Proc. Natl. Acad. Sci. U.S.A. 91, 7095-7098. doi: 10.1073/pnas.91.15.7095

Nieto, A., Pérez, D. G., Orozco, E., Paz, F., and Gómez, C. (2005). Entamoeba histolytica EhPgp5 transcriptional activation depends on putative emetine response elements. Exp. Parasitol. 110, 233-237. doi: 10.1016/j.exppara.2005.03.016

Orozco, E., López, C., Gómez, C., Pérez, D. G., Marchat, L., Ba-uelos, C., et al. (2001). Multidrug resistance in the protozoan parasite Entamoeba histolytica. Parasitol. Int. 51, 353-359. doi: 10.1016/S1383-5769(02)00 041-7 
Orozco, E., Suárez, M. E., and Sánchez, T. (1985). Differences in adhesion, phagocytosis and virulence of clones from Entamoeba histolytica, strain HM1:IMSS. Int. J. Parasitol. 15, 655-660. doi: 10.1016/0020-7519(85)90012-8

Pérez, D. G., Gómez, C., López-Bayghen, E., Tannich, E., and Orozco, E. (1998). Transcriptional analysis of the EhPgp5 promoter of Entamoeba histolytica multidrug-resistant mutant. J. Biol. Chem. 273, 7285-7292. doi: 10.1074/jbc.273.13.7285

Perisic, O., Xiao, H., and Lis, J. T. (1989). Stable binding of Drosophila heat shock factor to head-to-head and tail-to-tail repeats of a conserved 5 bp recognition unit. Cell 59, 797-806. doi: 10.1016/0092-8674(89)90603-X

Rabdiran, S. K., Giorgi, G., Clos, J., and Wu, C. (1991). Molecular cloning and expression of a human heat shock factor, HSF1. Proc. Natl. Acad. Sci. U.S.A. 88, 6906-6910. doi: 10.1073/pnas.88.16.6906

Romero-Díaz, M., Gómez, C., López-Reyes, I., Martínez, M. B., Orozco, E., and Rodríguez, M. A. (2007). Structural and functional analysis of the Entamoeba histolytica EhrabB gene promoter. BMC Mol. Biol. 8:82. doi: 10.1186/1471-2199-8-82

Sandqvist, A., Björk, J. K., Akerfelt, M., Chitikova, Z., Grichine, A., Vourc'h, C., et al. (2009). Heterotrimerization of heat-shock factors 1 and 2 provides a transcriptional switch in response to distinct stimuli. Mol. Biol. Cell 20, 1340-1347. doi: 10.1091/mbc.E08-08-0864

Sarge, K. D., Murphy, S. P., and Morimoto, R. I. (1993). Activation of heat shock gene transcription by heat shock factor 1 involves oligomerization, acquisition of DNA-binding activity, and nuclear localization and can occur in the absence of stress. Mol. Cell. Biol. 13, 1392-1407. doi: 10.1128/MCB.13 3.1392

Schreiber, E., Matthias, P., Müeller, M. M., and Schaffner, W. (1989). Rapid detection of octamer binding proteins with 'mini-extracts', prepared from a small number of cells. Nucleic Acid Res. 17:6419. doi: 10.1093/nar/17.15.6419

Schuetz, T. J., Gallo, G. J., Sheldon, L., Tempst, P., and Kingston, R. E. (1991). Isolation of a cDNA for HSF2: evidence for two heat shock factor genes in human. Proc. Natl. Acad. Sci. U.S.A. 88, 6911-6915. doi: $10.1073 /$ pnas.88.16.6911

Shi, Y., Seto, E., Chang, L. S., and Shenk, T. (1991). Transcriptional repression by YY1, a human GLI-Krüppel-related protein, and relief of repression by adenovirus E1A protein. Cell 67, 377-388. doi: 10.1016/0092-8674(91)90 189-6

Sorger, P. K., and Pelham, H. R. (1988). Yeast heat shock factor is an essential DNAbinding protein that exhibits temperature-dependent phosphorylation. Cell 54, 855-864. doi: 10.1016/S0092-8674(88)91219-6

Sorger, P. K., Lewis, M. J., and Pelham, H. R. (1987). Heat shock factor is regulated differently in yeast and HeLa cells. Nature 239, 81-84. doi: 10.1038/329081a0

Tchénio, T., Havard, M., Martinez, L. A., and Dautry, F. (2006). Heat Shockindependent induction of multidrug resistance by heat shock factor 1. Mol. Cell. Biol. 26, 580-591. doi: 10.1128/MCB.26.2.580-591.2006

World Health Organization (1998). The World Health Report 1998: Life in the 21st Century: a Vision for All. Geneva: World Health Organization.

Ximénez, C., González, E., Nieves, M., Maga-a, U., Morán, P., Gudiño-Zayas, M., et al. (2017). Differential expression of pathogenic genes of Entamoeba histolytica vs E. dispar in a model of infection using human liver tissue explants. PLoS ONE 12:e0181962. doi: 10.1371/journal.pone.0181962

Zou, J., Guo, Y., Guettouche, T., Smith, D. F., and Voellmy, R. (1998). Repression of heat shock transcription factor HSF1 activation by HSP90 (HSP90 complex) that forms a stress-sensitive complex with HSF1. Cell 94, 471-480 doi: 10.1016/S0092-8674(00)81588-3

Conflict of Interest Statement: The authors declare that the research was conducted in the absence of any commercial or financial relationships that could be construed as a potential conflict of interest.

The handling Editor declared a shared affiliation, though no other collaboration, with all the authors.

Copyright (c) 2017 Nieto, Pérez Ishiwara, Orozco, Sánchez Monroy and Gómez García. This is an open-access article distributed under the terms of the Creative Commons Attribution License (CC BY). The use, distribution or reproduction in other forums is permitted, provided the original author(s) or licensor are credited and that the original publication in this journal is cited, in accordance with accepted academic practice. No use, distribution or reproduction is permitted which does not comply with these terms. 